\title{
High hepatocyte growth factor expression in primary tumor predicts better overall survival in male breast cancer
}

Si-Qi Qiu ${ }^{1,2,3}$, Johan van Rooijen ${ }^{1,4}$, Hilde H. Nienhuis ${ }^{1}$, Bert van der Vegt ${ }^{5}$, Hetty Timmer-Bosscha', Elise van Leeuwen-Stok ${ }^{6}$, Annemiek M. E. Walenkamp ${ }^{1}$, Carolien H. M. van Deurzen ${ }^{7}$, Geertruida H. de Bock ${ }^{8}$, Elisabeth G. E. de Vries ${ }^{1}$ and Carolien P. Schröder ${ }^{1 *}$

\begin{abstract}
Background: Breast cancer is rare in men, but management is focused on tumor characteristics commonly found in female breast cancer. The tumor microenvironment of male breast cancer is less well understood, and insight may improve male breast cancer management. The hepatocyte growth factor (HGF)/c-MET axis and the stromal cell-derived factor-1 (CXCL12)/C-X-C chemokine receptor type 4 (CXCR4) axis are prognostic in women with breast cancer. We aimed to investigate these factors in male breast cancer and correlate them with patient survival.
\end{abstract}

Methods: From 841 Dutch males with breast cancer who were enrolled in the EORTC 10085/TBCRC/BIG/NABCG International Male Breast Cancer Program (NCT01101425) and diagnosed between 1990 and 2010, archival primary tumor samples were collected. Tissue microarrays were constructed with 3 cores per sample and used for immunohistochemical analysis of HGF, C-MET, CXCL12, and CXCR4. Overall survival (OS) of the patients without metastases (M0) was analyzed using the Kaplan-Meier method. The value of the markers regarding OS was determined using univariable and multivariable Cox regression analyses, providing hazard ratios (HRs) and 95\% confidence intervals (95\% Cls).

Results: Of 720 out of 841 patients, sufficient tissue was available for analysis; 487 out of 720 patients had M0 disease. Patients with high HGF expression and high CXCL12 expression had a superior OS (low vs high expression of both markers, 7.5 vs 13.0 years, hazard ratio [HR] 0.64, 95\% Cl 0.49-0.84, $P=0.001$ [HGF]; 9.1 vs 15.3 years, HR 0.63, 95\% Cl 0.45-0.87, $P=0.005$ [CXCL12]). Multivariate analysis identified HGF as an independent predictor for OS (HR $0.64,95 \% \mathrm{Cl} 0.47-0.88, P=0.001)$.

Conclusions: HGF and CXCL12 tumor expression appear to identify male breast cancer patients with a relatively good prognosis. Possibly, this could support male breast cancer-specific management strategies in the future.

Keywords: Male breast cancer, Hepatocyte growth factor (HGF), Stromal cell-derived factor-1 (CXCL12), Prognosis, Tumor biology

\footnotetext{
* Correspondence: c.p.schroder@umcg.nl

'Department of Medical Oncology, University of Groningen, University

Medical Center Groningen, PO Box 30.001, 9700 RB Groningen, The Netherlands

Full list of author information is available at the end of the article
}

(C) The Author(s). 2020 Open Access This article is licensed under a Creative Commons Attribution 4.0 International License, which permits use, sharing, adaptation, distribution and reproduction in any medium or format, as long as you give appropriate credit to the original author(s) and the source, provide a link to the Creative Commons licence, and indicate if changes were made. The images or other third party material in this article are included in the article's Creative Commons licence, unless indicated otherwise in a credit line to the material. If material is not included in the article's Creative Commons licence and your intended use is not permitted by statutory regulation or exceeds the permitted use, you will need to obtain permission directly from the copyright holder. To view a copy of this licence, visit http://creativecommons.org/licenses/by/4.0/ The Creative Commons Public Domain Dedication waiver (http://creativecommons.org/publicdomain/zero/1.0/) applies to the data made available in this article, unless otherwise stated in a credit line to the data. 


\section{Background}

Breast cancer in men is a rare disease. Although only $0.5-1 \%$ of all breast cancers occur in men, the incidence is slowly rising $[1,2]$. Generally, male breast cancer has more favorable tumor characteristics than female breast cancer, such as lower tumor grade, a higher incidence of estrogen receptor (ER) expression, and a lower incidence of human epidermal growth factor receptor 2 (HER2) expression [1, 3]. On the other hand, male patients present with higher stages of disease at first diagnosis than women $[1,4]$. Although the outcome in male breast cancer is similar compared to women after correction for age and stage, in general, survival improvement in men is still lagging behind [1, 4-7]. Due to the lack of survival data from randomized trials in male breast cancer, treatment strategies for this disease are largely based upon data from studies of treatment for female breast cancer. In recent years, it becomes clear that the male breast cancer biology may have distinct properties compared to females [8-11]. Therefore, a better understanding of the breast tumor characteristics in men may help to improve treatment strategies for male breast cancer.

The tumor microenvironment in female breast cancer is now recognized as a critical participant in determining the tumor biology. In this environment, the stromal cellderived factor-1 (SDF1, also known as CXCL12)/the C$\mathrm{X}-\mathrm{C}$ chemokine receptor type 4 (CXCR4) axis as well as the hepatocyte growth factor (HGF)/c-MET axis play a role in promoting tumor progression and metastasis, as demonstrated in ex vivo cell experiments and in vivo mouse models of breast cancer [12-14]. The HGF/cMET axis induces several biological responses in cancer cells, which lead to cell migration, matrix degradation, invasiveness, and induction of angiogenesis [15]. Moreover, overexpression of CXCR4, HGF, and c-MET in primary breast cancer is associated with worse patient outcomes in females $[14,16-20]$. Treatments targeting CXCR4 and c-MET in female metastatic breast cancer studied in early-phase clinical trials were tolerated well, and partial response and stable disease were observed [21-24].

However, whether the CXCL12/CXCR4 and the HFG/ c-MET axis hold similar significance in male breast cancer is unknown. These microenvironment factors are of interest because the host/environment in male breast cancer will likely be different from female breast cancer.

In order to gain more insight into the male breast cancer tumor and environment biology, we studied a large male breast cancer cohort from The Netherlands. This cohort is part of the international EORTC 10085/ TBCRC/BIG/NABCG International Male Breast Cancer Program (NCT01101425). We aimed to explore the tumor expression of HGF, c-MET, CXCL12, and CXCR4 and their correlation with patient overall survival (OS).

\section{Methods}

\section{Patients}

The EORTC 10085/TBCRC/BIG/NABCG International Male Breast Cancer Program (NCT01101425) was launched in 2006. This program is a global effort that aims to improve understanding of the biology of male breast cancer and to optimize its clinical management. An important part of this program was to retrospectively analyze male breast cancer tissue of patients diagnosed between 1990 and 2010 in 93 centers in nine countries. A total of 1800 male patients with invasive breast cancer and an age above 18 years at the time of diagnosis, were eligible and enrolled in the main study. The present substudy analyzed the data of the 841 Dutch patients included. This cohort was identified through the Netherlands Cancer Registry. Patient, treatment, and tumor characteristics were collected from the EORTC database. In the tumor, ER, progesterone receptor (PR), androgen receptor (AR), HER2 and Ki67 expression, histological subtype, grade, and lymphovascular invasion had been previously centrally reviewed [25, 26]. Definitions for positivity of ER, PR, AR, and HER2, and breast cancer subtype surrogate characterization were reported earlier for all 1800 enrolled patients [26]. Briefly, ER, PR, and AR were reported by Allred scores, with positivity defined as a score $\geq 3$ and high positivity as a score of 7 or 8. HER2 status was determined according to the American Society of Clinical Oncology-College of American Pathologist (ASCO-CAP) guidelines [26]. Breast cancer subtype surrogates were characterized according to the 2013 St. Gallen consensus guideline, where the low level of Ki67 expression was reported as the percentage of positive cells $<20 \%$ and high level of Ki67 expression as $\geq 20 \%$ [26]. The archival tissue of all patients was handled according to the Dutch Code for Proper Use of Human Tissue (www.fedara.org). According to the Dutch Central Committee on Research involving Human Subjects, this retrospective non-interventional study did not require informed consent from these patients.

\section{Tissue microarray construction and immunohistochemistry}

Paraffin-embedded primary breast cancer tissue was retrospectively collected by the "Borstkanker Onderzoek Groep" (BOOG). For each formalin-fixed paraffinembedded (FFPE) block, three representative cores were selected and taken to construct tissue microarrays (TMA) using an Automated Tissue Arrayer ATA-27 (Beecher Instruments, Inc.) [27]. Four-micrometer-thick tissue slides were cut from these TMA blocks for immunohistochemical staining of HGF, c-MET, CXCL12, and CXCR4.

Immunohistochemical staining was performed in one batch per marker to prevent intensity differences. 
Positive control slides determined with primary antibodies and negative control slides with immunoglobulin class-matched control sera were included on the liver for HGF, female breast cancer tissue for c-MET, rectum for CXCL12, and kidney for CXCR4. Besides this, we also included intestine, heart, brain, liver, lung, stomach, kidney, pancreas, placenta, muscle, testis, and tonsil tissues in each of the TMA slides as the internal control. These tissues express different levels of the studied markers, supporting the specificity of the antibodies. Heat-mediated antigen retrieval was performed with a microwave in a citrate buffer $(10 \mathrm{mM}$ citrate, $\mathrm{pH}$ 6.0) for CXCL12 and Tris-EDTA buffer ( $\mathrm{pH}$ 8.0) for HGF and c-MET. Antigen retrieval was not performed for CXCR4 staining. Endogenous peroxidase was blocked with $0.3 \% \mathrm{H}_{2} \mathrm{O}_{2}$ in phosphatebuffered saline (PBS; $\mathrm{Cl}_{2} \mathrm{H}_{3} \mathrm{~K}_{2} \mathrm{Na}_{3} \mathrm{O}_{8} \mathrm{P}_{2}, \mathrm{pH}$ 7.4). A specific binding was blocked with human $\mathrm{AB}$ serum. Primary antibodies (anti-HGF [28]: AF-294-NA [10 $\mu \mathrm{g} / \mathrm{ml}]$, R\&D Systems; anti-c-MET [29]: ab51067 [1.269 $\mu \mathrm{g} / \mathrm{ml}]$, anti-CXCR4 [30]: ab10403 [5 $\mu \mathrm{g} / \mathrm{ml}]$, anti-CXCL12 [31]: ab25117 $[10 \mu \mathrm{g} / \mathrm{ml}]$, all Abcam) were diluted in PBS supplemented with $1 \%$ bovine serum albumin. Horseradish peroxidase (HRP)-conjugated goat anti-rabbit and HRP-conjugated rabbit anti-goat antibodies (DAKO) were used as secondary and tertiary antibodies respectively for CXCL12 and cMET staining. HRP-conjugated rabbit anti-goat and HRPconjugated goat anti-rabbit antibodies were used as secondary and tertiary antibodies (DAKO), respectively, for HGF staining. Staining was visualized using 3,3'-diaminobenzidine and hematoxylin counterstaining.

The immunohistochemistry slides were digitized with a Digital Slide Scanner NanoZoomer and were viewed with NDP software (Hamamatsu, Japan). Only the patients who had two or more cores containing tumor and stromal cells were included for analysis. Two observers, blinded for the clinicopathological characteristics of patients, scored the digitalized images (SQ and JvR) with the supervision of a dedicated breast pathologist (BvdV). CXCL12, HGF, and c-MET staining was scored using a $0-2$ scale $(0$, no staining; $1+$, weak staining; $2+$, strong staining), as was the percentage of tumor cells stained per intensity. Subsequently, $H$-scores were calculated for

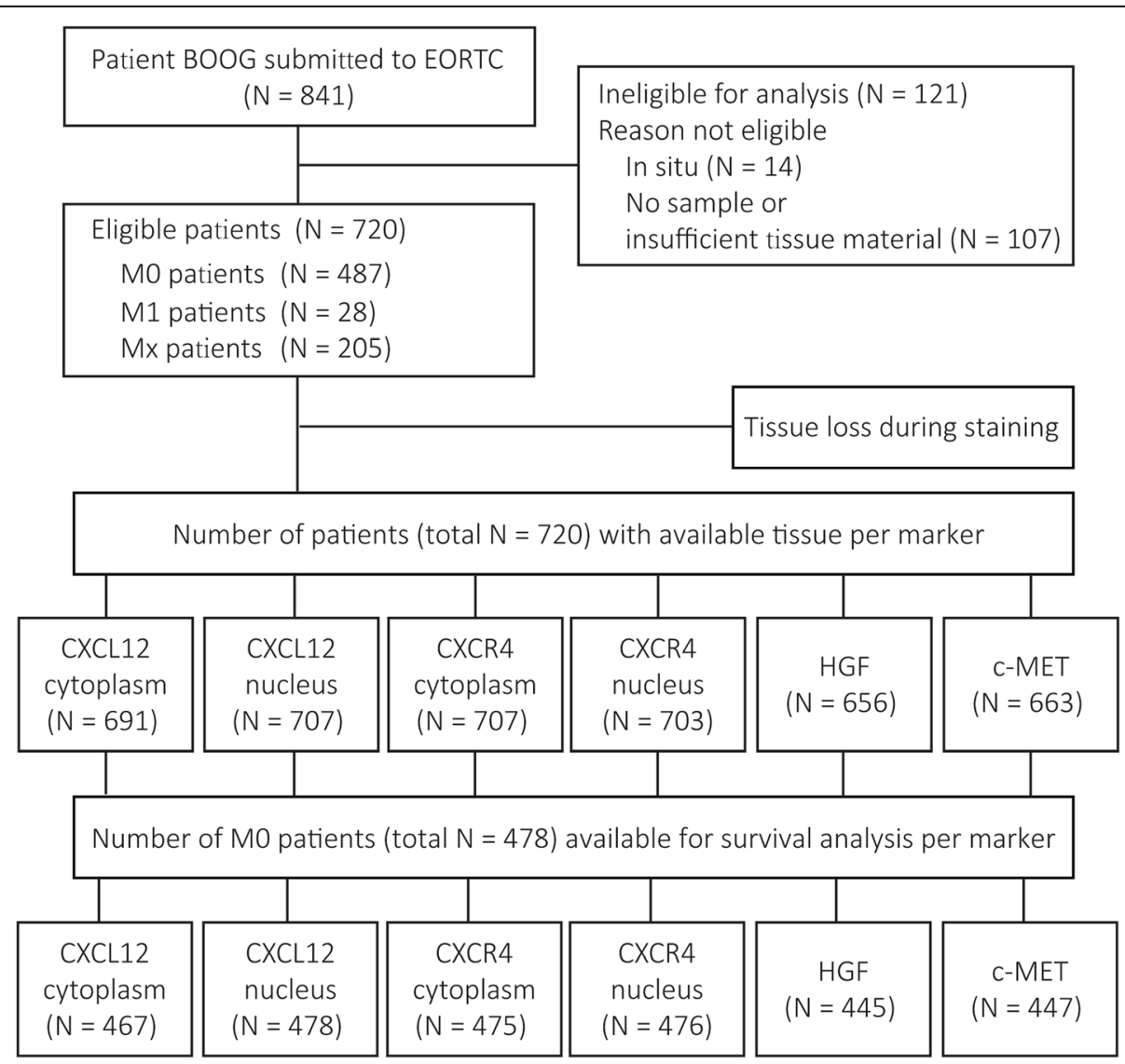

Fig. 1 CONSORT diagram of the studied patients, number of patients with available tissue for each marker, and number of M0 patients per marker available for survival analysis. BOOG, Borstkanker Onderzoek Groep; EORTC, European Organisation for Research and Treatment of Cancer; CXCR4, C-X-C chemokine receptor type 4; CXCL12, C-X-C motif chemokine 12; HGF, hepatocyte growth factor; M0, patients without metastases at diagnosis; M1, patients with metastases at diagnosis; Mx, patients with unknown metastatic status at diagnosis 
Table 1 Patient and tumor characteristics of 720 male breast cancer patients with sufficient tumor tissue available for analysis

\begin{tabular}{lll}
\hline Characteristics & No. (\%) & \% exclude missing \\
\hline
\end{tabular}

\section{Age at diagnosis}

Median (IQR)

$67(58-76)$ years

ER (Allred score)

$0-2$

3-6

$7-8$

Missing

PR (Allred score)

$0-2$
$3-6$
$7-8$
Missing

AR (Allred score)

$\begin{array}{ll}0-2 & 20(2.8) \\ 3-6 & 62(8.7) \\ 7-8 & 556(77.2) \\ \text { Missing } & 82(11.4)\end{array}$

HER2 status

$\begin{array}{lll}\text { Negative } & 597(82.9) \\ \text { Positive } & 31(4.3) & \text { (94.0) } \\ \text { Equivocal } & 7(1.0) \\ \text { Missing } & 85(11.8) \\ \text { Ki67 } & \\ \leq 20 \% & 502(69.7) \\ >20 \% & 133(18.5) \\ \text { Missing } & 85(11.8)\end{array}$

Breast cancer subtypes (2013 St. Gallen consensus)

$\begin{array}{lll}\text { Luminal A-like } & 270(37.5) & (43.3) \\ \text { Luminal B-like HER2- } & 311(43.2) & (49.9) \\ \text { Luminal B-like HER+ } & 31(4.3) & (5.0) \\ \text { HER2+ (non-luminal) } & 0(0) & (0) \\ \text { Triple-negative } & 9(1.3) & (1.4) \\ \text { Not defined (ER-, PR+) } & 2(0.3) \\ \text { Missing } & 97(13.5)\end{array}$

Histological type

$\begin{array}{lll}\text { Invasive ductal } & 628(87.2) & (88.3) \\ \text { Invasive lobular } & 9(1.3) & (1.3) \\ \text { Others } & 74(10.3) & \\ \text { Missing } & 9(1.3) \\ \text { Histological grade } & \\ \text { I } & 165(22.9) \\ \text { II } & 373(51.8) \\ \text { III } & 172(23.9)\end{array}$

Table 1 Patient and tumor characteristics of 720 male breast cancer patients with sufficient tumor tissue available for analysis (Continued)

\begin{tabular}{lll}
\hline Characteristics & No. (\%) & \% exclude missing \\
\hline Missing & $10(1.4)$ & \\
Metastatic status at diagnosis & \\
M0 & $487(67.6)$ & \\
M1 & $28(3.9)$ & \\
Mx & $205(28.5)$ & \\
\hline
\end{tabular}

$A R$ androgen receptor, ER estrogen receptor, HER2 human epidermal growth factor receptor 2, IQR interquartile range, $M 0$ no metastasis, $M 1$ with metastasis, $M x$ metastatic status unknown, $P R$ progesterone receptor

each marker by combining the percentage and intensity (formula used: $1 \times$ percentage of cells with weak staining + $2 \times$ percentage of cells with strong staining). CXCR4 staining was scored as the percentage of tumor cells with a positive nuclear and with a cytoplasm staining, as the intensity of CXCR4 staining was too homogeneous to use the $0-2$ scale. The percentages or $H$-scores from two observers were averaged to obtain the score for each core. In case of discrepancy (defined as $>20 \%$ difference in percentage or $H$-score), a third observer who was blinded to the scores obtained from the two observers re-scored the cores. For these discrepant cores, a consensus score obtained from SQ and JvR was used, based on the scores from the three observers. The average percentage or $\mathrm{H}$ score of replicate cores was used as the final score for each patient. The median percentage or $H$-score of each studied marker was used as the cutoff to define low and high expression. The studied markers were also expressed in some stromal cells, such as the fibroblasts. However, the staining intensity of the markers in stromal cells was far weaker than their staining intensity in the tumor cells. Therefore, in this study, we did not explore the prognostic value of the studied markers expressed in the stromal cells.

\section{Statistical analysis}

The categorical variables were described by percentages, and continuous variables by median and interquartile range (IQR).

OS was defined as the time between the date of diagnosis and the documented date of death due to any cause. The remaining patients were censored at the last date known to be alive. OS was only defined within the subset of M0 patients at diagnosis, as the sample size of M1 patient group was too small to draw conclusions. Patients with unknown metastastic status $(\mathrm{Mx})$ at the time of diagnosis were also excluded from the OS analysis, as the metastastic status largely influence the patient survival. Only patients with non-missing status/dates of survival were used for the OS analysis. The prognostic value of the markers was determined using univariable 
and multivariable Cox regression analysis. Variables with a $P$ value of less than 0.1 in the univariable analysis were included in the multivariable analysis. We used the listwise deletion method for handling missing data. In this method, an entire sample was excluded from the analysis if any single value is missing for the variables used in the multivariable Cox regression analysis. For the studied markers which were not associated with patient survival in the univariable analysis, their prognostic values were further investigated in the preplanned subgroup analyses. OS was analyzed using the Kaplan-Meier method, with a log-rank test assessing its difference. All tests and $P$ values tested two-sided were considered significant when $\leq 0.05$. Statistical analysis was performed using the Statistical Package for the Social Sciences (SPSS) version 19.0 (SPSS. Inc.).

\section{Results}

\section{Patient and tumor characteristics}

In 720 out of the 841 patients, sufficient tumor tissue was available for analysis (Fig. 1). Patient and tumor characteristics at the time of diagnosis of these 720 patients are shown in Table 1. The median age at diagnosis of breast cancer was 67 years (IQR, 58-76 years). Almost all patients had ER-positive tumors (98.3\%), with 91.0\% highly positive. PR positivity was observed in $76.8 \%$ and AR positivity in $96.9 \%$ of cases. HER2 positivity was present in tumors of 31 patients (4.9\%). The majority of patients had a luminal-like breast cancer subtype, with 43.3\% luminal A-like and 49.9\% luminal B-like HER2-. There were $487(67.6 \%)$ patients that were free from metastasis (M0) at the time of diagnosis. The treatment information of these 487 patients is provided in
Additional file 1 . The median follow-up for the M0 patients was 6.5 years (range, 0.04-23.8).

\section{Expression of the studied markers in the primary tumor} The exact number of tumors tested per marker is shown in Fig. 1. Representative images of positive or negative expression for CXCR4, and negative, weak, or strong staining for CXCL12, HGF, and c-MET are shown in Additional file 2. The concordance rates of the percentage $/ H$-score for each TMA core (defined as $\leq 20 \%$ difference in percentage or $H$-score) among the studied markers between the two observers are shown in Additional file 3. The percentage of positive cells for CXCR4 expression and $H$-score for CXCL12, HGF, and c-MET are demonstrated in Fig. 2. The median CXCR4 expression per tumor was $50 \%$ (IQR, 18-83\%) in the cytoplasm and $11 \%$ (IQR, $0-42 \%$ ) in the nucleus. The median $\mathrm{H}$ score for the CXCL12 expression in the cytoplasm was 100 (IQR, 83-102) and 100 (IQR, 92-107) for the nucleus expression. The median $\mathrm{H}$-scores for HGF and cMET expression were 106 (IQR, 83-133) and 155 (IQR, 130-180), respectively. Information on the heterogeneity of the studied markers between the cores is provided in Additional files 4, 5, 6, and 7 .

\section{Prognostic value of the studied markers for OS in MO patients}

The exact number of M0 patients with available data for survival analysis is shown in Fig. 1. Both HGF and CXCL12 (cytoplasm) expression by tumor cells were correlated to OS in univariable Cox regression analysis, and HGF remained significant in the multivariable analysis (Fig. 3). Median OS was 7.5 years (95\% CI, 6.1-8.9) for patients with HGF low-expressing tumors and 13.0

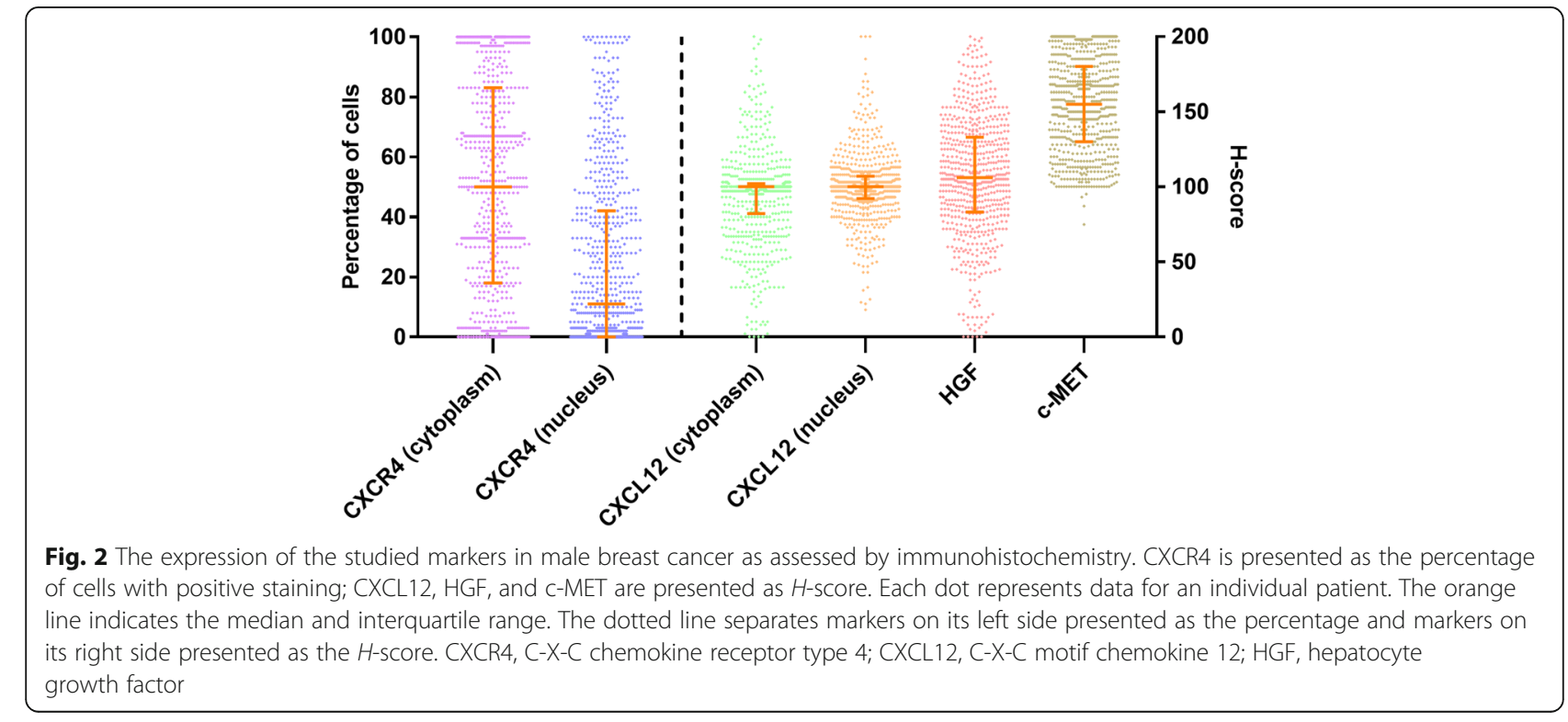




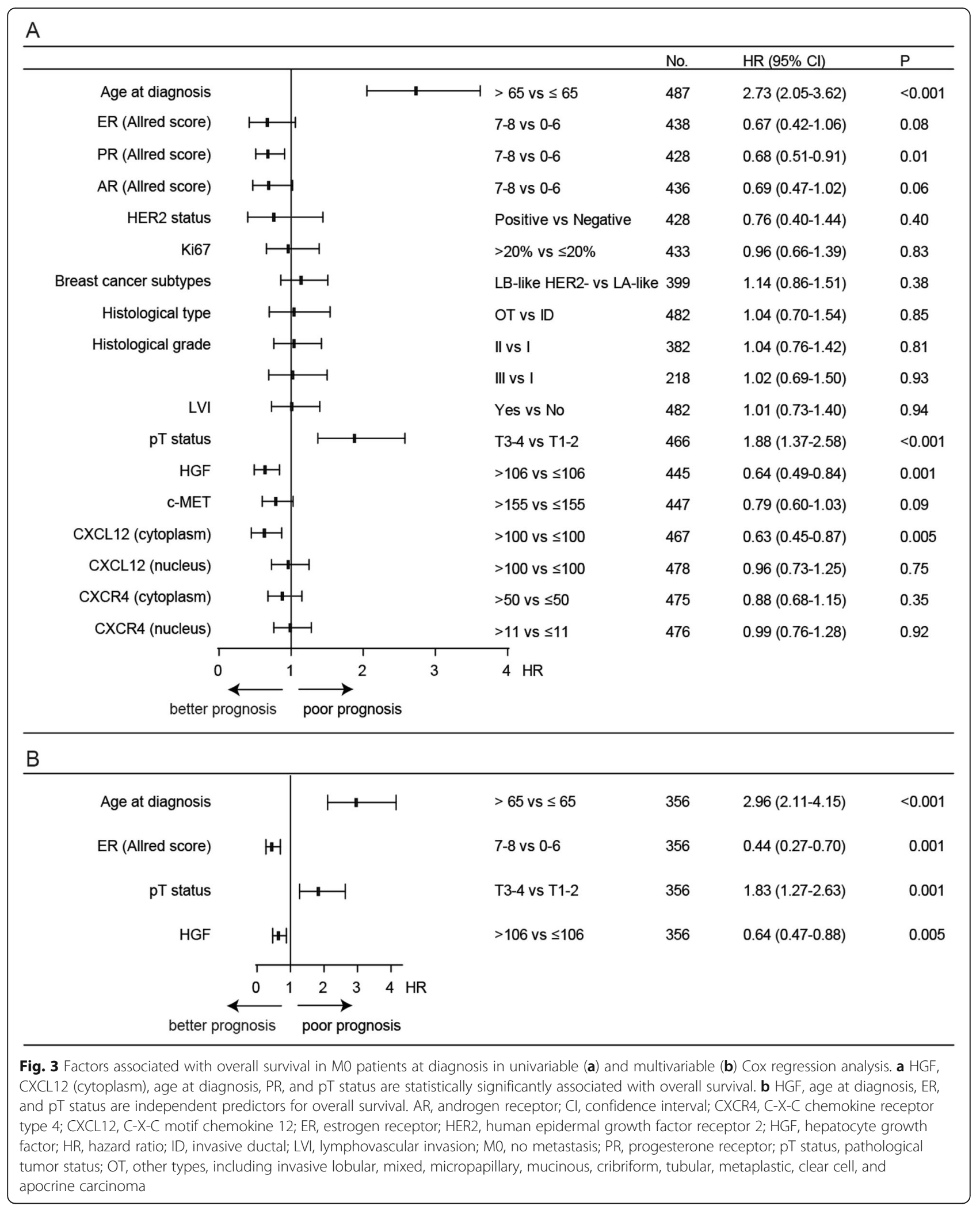


years (95\% CI, 9.8-16.2) for those with HGF highexpressing tumors [hazard ratio (HR), 0.64 (95\% CI, $0.49-0.84), P=0.001$ ]. Median OS was 9.1 years $(95 \% \mathrm{CI}$, 7.7-10.6) for patients with CXCL12 (cytoplasm) lowexpressing tumors and 15.3 years (95\% CI, 12.3-18.3) for those with CXCL12 (cytoplasm) high-expressing tumors [HR, 0.63 (95\% CI, 0.45-0.87), $P=0.005$ ] (Fig. 4). In the subgroup analysis, c-MET was correlated to OS in the subgroups with patients older than 65 years at diagnosis, PR low-expressing tumors, luminal B-like HER2- breast cancer subtype, invasive ductal tumors, and histological grade II tumors (see Additional file 8). CXCL12 (nucleus), CXCR4 (cytoplasm), and CXCR4 (nucleus) were not associated with $O S$ in any patient or tumor subgroup in the univariable analysis (see Additional files 9, 10, and 11). Based on these findings, we further classified patients according to the expression of HGF and cMET. The median OS of patients with both HGF and cMET low-expressing tumors was 6.6 years (95\% CI, 5.97.3), which was shorter than the OS of the other subgroups (Fig. 5). Age at diagnosis, PR, and pT status were the other parameters associated with OS (Fig. 3).

\section{Discussion}

In this unique cohort of male breast cancer patients, we identified HGF expression in the primary tumor to be an independent predictor for better OS in the nonmetastatic setting. In addition, high expression of CXCL12 in the cytoplasm of tumor cells in the primary tumor was associated with better OS.

Remarkably, the prognostic value of HGF and c-MET is contradictory to the findings in female breast cancer. In female breast cancer, HGF and c-MET have been identified as a predictor for worse outcomes and are associated with a high Ki-67 labeling index [14, 16-19].
This led to the hypothesis that HGF acts as a mitogen in female breast cancer [32]. In our cohort in male breast cancer, we identified HGF to be an independent prognostic factor for better OS.

The prognostic value of the CXCL12 expression in male breast cancer is comparable with the findings in female breast cancer reported in the literature [33, 34]. In female breast cancer, the cytoplasmic expression of CXCL12 was associated with better disease-free survival and OS [33, 34]. These results are confirmed by a recently published meta-analysis, which included 8 studies with a total of 2205 patients [35]. Four of these studies $(N=953)$ measured the CXCL12 protein expression which was positively correlated with disease-free survival and OS.

The remarkable difference in the prognostic value of HGF and c-MET compared to female breast cancer might result from differences in tumor and environment biology between male and female breast cancer. This is in line with a recent study of DNA sequencing analysis on 1943 cancer-related genes in 135 patients with male breast cancer, which demonstrated differences in the genomic landscape between male and female breast cancers. Somatic mutations in homologous recombination deficiency-related genes were more prevalent in male breast cancer compared to female breast cancer, whereas TP53 somatic mutations were less frequent [36]. Currently, it becomes clear that some important markers in breast cancer biology can play a different role in male compared to female breast cancer. When dependency patterns of key oncoproteins were compared between 134 male and 728 female breast cancer tissues, some similar patterns were observed for both genders, such as p53 and hypoxia-inducible factor 1-alpha [8]. However, also clear differences were identified. For example, the
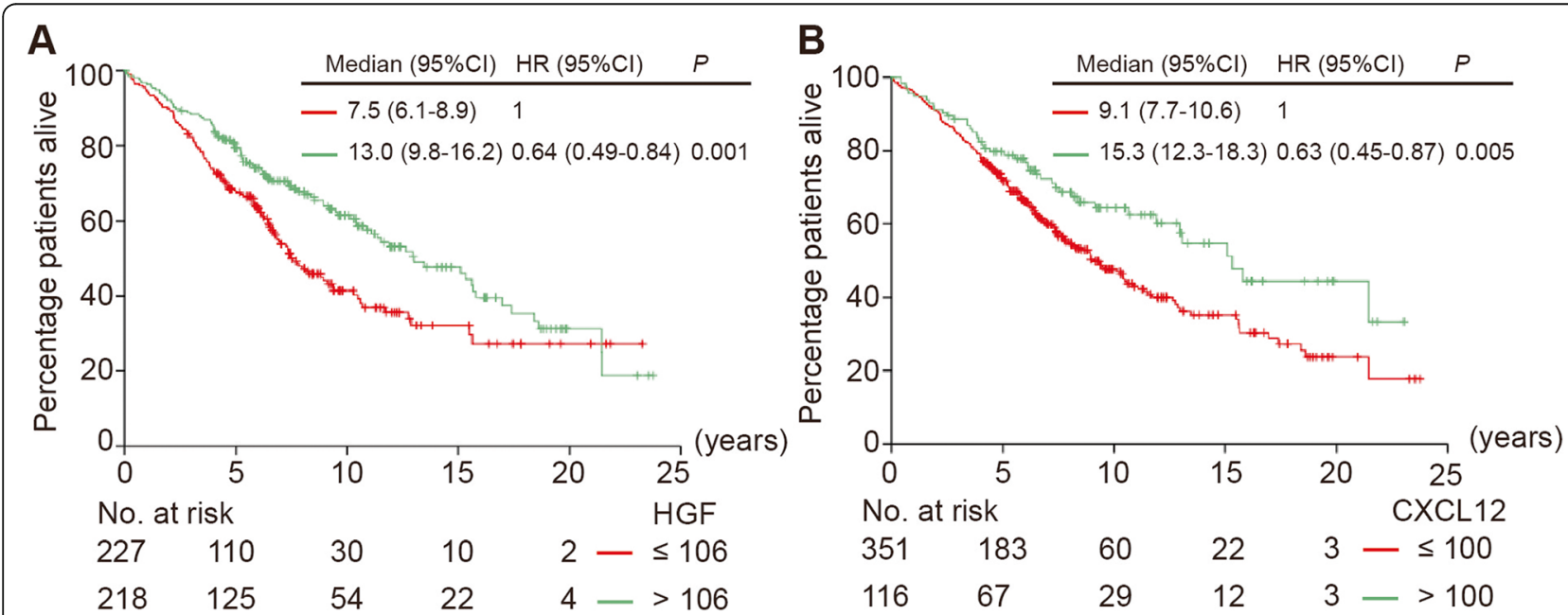

Fig. 4 Kaplan-Meier analysis for the overall survival of M0 patients at diagnosis classified by HGF and CXCL12 (cytoplasm) tumor expression. CXCL12, C-X-C motif chemokine 12; HGF, hepatocyte growth factor; M0, no metastasis 


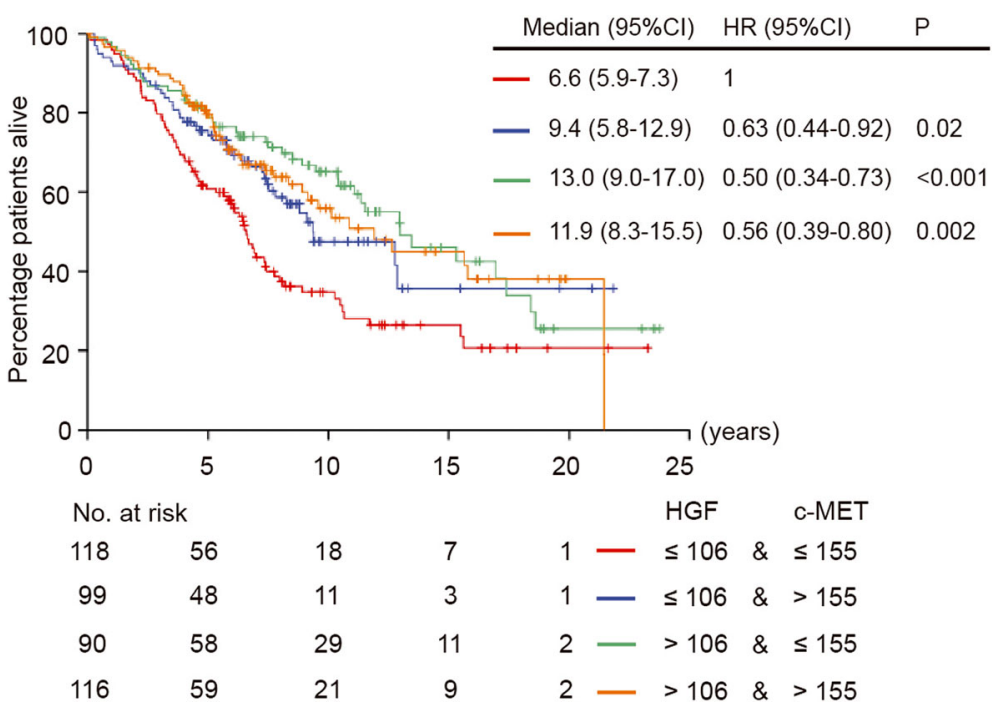

Fig. 5 Kaplan-Meier analysis for overall survival of MO patients at diagnosis classified by HGF and c-MET tumor expression. Cl, confidence interval; $\mathrm{HGF}$, hepatocyte growth factor; HR, hazard ratio; $\mathrm{MO}$, no metastasis

expression of PR showed in female breast cancer a continuous dependency on cytokeratin $8 / 18$, cyclin D1, B cell lymphoma 2 (Bcl-2), and cyclin-dependent kinase inhibitor p21 [8]. In male breast cancer, however, PR showed no dependency on these markers, indicating that PR is subject to effects from other markers [8]. AR had a stronger effector function in males compared to female tumors [8]. Results from the 21-gene breast recurrence score, used to characterize the molecular features of breast cancer, also indicate distinct differences in male compared to female breast cancer. Men below 40 years of age had a higher recurrence score compared to females while above 60 years men had a larger proportion with a low recurrence score [10]. Therefore, although differences between male and female breast cancer become apparent, the crosstalk among predominant biologic pathways and their function in males is not well understood, including that of the HGF/c-MET signaling.

In female breast cancer, $\mathrm{HGF} / \mathrm{c}-\mathrm{MET}$ promotes cell proliferation, migration, and invasion by HGF bindinginduced c-MET activation of the phosphoinositide 3kinase/Akt pathway and the Erk/mitogen-activated protein kinase cascade [14]. Furthermore, high expression of HGF or c-MET was associated with higher histological tumor grade and worse patient outcomes [16, 19]. In the present study, higher expression of both HGF and c-MET was associated with improved OS. One possible factor contributing to this difference might be the age difference between male and female breast cancer patients. Preclinical evidence suggests that with advancing age, the tumor stroma exhibits alterations, such as decreased interferon signaling and antigen presentation. These changes may influence the proliferative effects of the tumor microenvironment [37]. The influence of age on the tumor microenvironment needs to be further elucidated but might lead to new insight into the dynamics of the tumor microenvironment.

Our study has limitations. First, due to its retrospective nature, data of some patient and tumor characteristics are missing. Nevertheless, the number of M0 patients excluded for the OS analysis was limited, and therefore, a significant impact on our findings appears unlikely. Second, currently, there is no widely accepted standardized methodology for immunohistochemical staining and the scoring of the studied markers. This may create bias in interpreting the data. These issues can be addressed in the prospective Male Breast Cancer Program prospective part (NCT01101425), which has finalized the inclusion and of which analyses are ongoing.

\section{Conclusions}

In the present study, HGF and CXCL12 tumor expression identified male breast cancer patients with good prognosis. Whether this insight provides possible options for intervention strategies should be determined in future studies.

\section{Supplementary information}

Supplementary information accompanies this paper at https://doi.org/10 1186/s13058-020-01266-X.

Additional file 1: Table S1. Pattern of treatment for 487 patients without metastasis at diagnosis.

Additional file 2: Figure S1. Examples of negative and positive staining of CXCR4; negative, weak (1+) and strong (2+) staining of CXCL12, HGF and C-MET by immunohistochemistry. Abbreviations: CXCL12, C-X-C motif chemokine 12; CXCR4, C-X-C chemokine receptor type 4 ; HGF, hepatocyte growth factor. 
Additional file 3: Table S2. The concordance rates of the percentage/ $\mathrm{H}$-score for each TMA core among the studied markers between the two observers.

Additional file 4. Information on the heterogeneity of percentage of positive cells for CXCR4 between the TMA cores.

Additional file 5. Information on the heterogeneity of $\mathrm{H}$-score for CXCL12 between the TMA cores.

Additional file 6. Information on the heterogeneity of $\mathrm{H}$-score for HGF between the TMA cores.

Additional file 7. Information on the heterogeneity of $\mathrm{H}$-score for $\mathrm{C}$ MET between the TMA cores.

Additional file 8: Figure S2. Subgroup analysis by patient and tumor characteristics of the prognostic value of c-MET for overall survival in patients without metastasis. C-MET is associated with overall survival in the subgroups with patients older than 65 years at diagnosis, PR low expression tumors, Luminal B-like HER2- breast cancer subtype, invasive ductal tumors and histological grade II tumors. Abbreviations: AR, androgen receptor, $\mathrm{Cl}$, confidence interval; ER: estrogen receptor; HR, hazard ratio; PR, progestrone receptor; PT status: pathological tumor status.

Additional file 9: Figure S3. Subgroup analysis by patient and tumor characteristics of the prognostic value of CXCL12 (nucleus) for overall survival in patients without metastasis. CXCL12 (nucleus) is not associated with overall survival in any subgroup. Abbreviations: AR, androgen receptor, Cl, confidence interval; CXCL12, C-X-C motif chemokine 12; ER: estrogen receptor; HR, hazard ratio; PR, progestrone receptor; pT status: pathological tumor status.

Additional file 10: Figure S4. Subgroup analysis by patient and tumor characteristics of the prognostic value of CXCR4 (cytoplasm) for overall survival in patients without metastasis. CXCR4 (cytoplasm) is not associated with overall survival in any subgroup. Abbreviations: $A R$, androgen receptor, $\mathrm{Cl}$, confidence interval; CXCR4, C-X-C chemokine receptor type 4; ER: estrogen receptor; $H R$, hazard ratio; PR, progestrone receptor; pT status: pathological tumor status.

Additional file 11: Figure S5. Subgroup analysis by patient and tumor characteristics of the prognostic value of CXCR4 (nucleus) for overall survival in patients without metastasis. CXCR4 (nucleus) is not associated with overall survival in any subgroup. Abbreviations: AR, androgen receptor, Cl, confidence interval; CXCR4, C-X-C chemokine receptor type 4; ER: estrogen receptor; HR, hazard ratio; PR, progestrone receptor; PT status: pathological tumor status.

\section{Abbreviations}

AR: Androgen receptor; ASCO-CAP: American Society of Clinical OncologyCollege of American Pathologist; BCl-2: B cell lymphoma 2;

BOOG: Borstkanker Onderzoek Groep; CXCL12 (SDF1): Stromal cell-derived factor-1; CXCR4: C-X-C chemokine receptor type 4; ER: Estrogen receptor; FFPE: Formalin-fixed paraffin-embedded; HER2: Human epidermal growth factor receptor 2; HGF: Hepatocyte growth factor; HR: Hazard ratio; HRP: Horseradish peroxidase; IQR: Interquartile range; OS: Overall survival; PBS: Phosphate-buffered saline; PR: Progesterone receptor; SPSS: Statistical Package for the Social Sciences; TMA: Tissue microarrays

\section{Acknowledgements}

We would like to thank Linda Pot, Coralie Poncet, and Fatima Cardoso for their kind assistance in immunohistochemical staining and data collection and their constructive comments for this study.

\section{Authors' contributions}

SQ designed the study, performed the data acquisition, analyzed and interpreted the data, and drafted the manuscript. JVR performed the data acquisition, interpreted the data, and drafted the manuscript. HN and HTB performed the data acquisition and critically revised the manuscript. BvdV was involved in the scoring of the studied markers and critically revised the manuscript. EvLS, AW, CvD, and GdB supervised parts of the study and critically revised the manuscript. EdV and CS designed and supervised the study, interpreted the data, and drafted the manuscript. All authors reviewed the final manuscript.

\section{Funding}

This study is supported by the Abel Tasman Talent Program (ATTP) of the University of Groningen, the Guangdong Province General University Key Research Platform and Research Program (2018KQNCX084), and the Natural Science Foundation Committee (81901801) to SQ; the Dutch Cancer Society grant RUG 2010-4739 and 2010 Dutch Pink Ribbon Foundation grant Male Breast to CS; and the PR grant (2010.WO25.C63). The funding bodies did not participate in the design of the study; the collection, analysis, or interpretation of the data; the writing of the manuscript; or the decision of manuscript submission.

\section{Availability of data and materials}

The datasets generated during and/or analyzed during the current study are available from the corresponding author on reasonable request.

\section{Ethics approval and consent to participate}

The archival tissue of all patients was handled according to the Dutch Code for Proper Use of Human Tissue (www.fedara.org). According to the Dutch Central Committee on Research involving Human Subjects, this retrospective non-interventional study did not require informed consent from these patients.

\section{Consent for publication}

Not applicable.

\section{Competing interests}

The authors declare that they have no competing interests.

\section{Author details}

${ }^{1}$ Department of Medical Oncology, University of Groningen, University Medical Center Groningen, PO Box 30.001, 9700 RB Groningen, The Netherlands. ${ }^{2}$ Diagnosis and Treatment Center of Breast Diseases, Affiliated Shantou Hospital, Sun Yat-sen University, Shantou, China. ${ }^{3}$ The Breast Center, Cancer Hospital of Shantou University Medical College, Shantou, China. ${ }^{4}$ Department of Internal Medicine, Martini Hospital Groningen, Groningen, The Netherlands. ${ }^{5}$ Department of Pathology, University of Groningen, University Medical Center Groningen, Groningen, The Netherlands. ${ }^{6} \mathrm{BOOG}$ Study Center, Amsterdam, The Netherlands. ${ }^{7}$ Department of Pathology, Erasmus MC Cancer Institute, Rotterdam, The Netherlands. ${ }^{8}$ Department of Epidemiology, University of Groningen, University Medical Center Groningen, Groningen, The Netherlands.

Received: 9 November 2019 Accepted: 9 March 2020 Published online: 18 March 2020

\section{References}

1. Giordano SH. Breast cancer in men. N Engl J Med. 2018:378:2311-20.

2. Ruddy KJ, Winer EP. Male breast cancer: risk factors, biology, diagnosis, treatment, and survivorship. Ann Oncol. 2013;24:1434-43.

3. Giordano SH, Cohen DS, Buzdar AU, Perkins G, Hortobagyi GN. Breast carcinoma in men: a population-based study. Cancer. 2004;101:51-7.

4. Sirieix J, Fraisse J, Mathoulin-Pelissier S, Leheurteur M, Vanlemmens L, Jouannaud C, et al. Management and outcome of metastatic breast cancer in men in the national multicenter observational ESME program. Ann Oncol. 2018;29 Abstract 294PD_PR.

5. Anderson WF, Jatoi I, Tse J, Rosenberg PS. Male breast cancer: a populationbased comparison with female breast cancer. J Clin Oncol. 2010;28:232-9.

6. Liu N, Johnson KJ, Ma CX. Male breast cancer: an updated surveillance, epidemiology, and end results data analysis. Clin Breast Cancer. 2018;18: e997-1002.

7. Miao H, Verkooijen HM, Chia KS, Bouchardy C, Pukkala E, Larønningen S, et al. Incidence and outcome of male breast cancer: an international population-based study. J Clin Oncol. 2011;29:4381-6.

8. Kornegoor $\mathrm{R}$, van Diest PJ, Buerger $\mathrm{H}$, Korsching E. Tracing differences between male and female breast cancer: both diseases own a different biology. Histopathology. 2015;67:888-97.

9. Manson QF, Hoeve ND, Buerger H, Moelans CB, van Diest PJ. PD-1 and PD$\mathrm{L} 1$ expression in male breast cancer in comparison with female breast cancer. Target Oncol. 2018;13:769-77.

10. Massarweh SA, Sledge GW, Miller DP, Mccullough D, Petkov VI. Molecular characterization and mortality from breast cancer in men. J Clin Oncol. 2018;36:1396-404 
11. Ottini L. Male breast cancer: a rare disease that might uncover underlying pathways of breast cancer. Nat Rev Cancer. 2014;14:643-4.

12. Bendinelli $P$, Maroni $P$, Matteucci E, Desiderio MA. Epigenetic regulation of HGF/Met receptor axis is critical for the outgrowth of bone metastasis from breast carcinoma. Cell Death Dis. 2017;8:e2578.

13. Domanska UM, Kruizinga RC, Nagengast WB, Timmer-Bosscha H, Huls G, de Vries EGE, et al. A review on CXCR4/CXCL12 axis in oncology: no place to hide. Eur J Cancer. 2013;49:219-30.

14. Ho-Yen CM, Jones JL, Kermorgant S. The clinical and functional significance of c-Met in breast cancer: a review. Breast Cancer Res. 2015;17:52

15. Parr C, Ali AY. Boswellia frereana suppresses HGF-mediated breast cancer cell invasion and migration through inhibition of c-Met signalling. J Transl Med. 2018;12:281

16. Zhao X, Qu J, Hui Y, Zhang H, Sun Y, Liu X, et al. Clinicopathological and prognostic significance of c-Met overexpression in breast cancer. Oncotarget. 2017;8:56758-67.

17. Garcia S, Dalès JP, Charafe-Jauffret E, Carpentier-Meunier S, Andrac-Meyer L, Jacquemier J, et al. Poor prognosis in breast carcinomas correlates with increased expression of targetable CD146 and c-Met and with proteomic basal-like phenotype. Hum Pathol. 2007;38:830-41.

18. Edakuni G, Sasatomi E, Satoh T, Tokunaga O, Miyazaki K. Expression of the hepatocyte growth factor/c-Met pathway is increased at the cancer front in breast carcinoma. Pathol Int. 2001:51:172-8.

19. Yang $H$, Zhang $C$, Cui S. Expression of hepatocyte growth factor in breast cancer and its effect on prognosis and sensitivity to chemotherapy. Mol Med Rep. 2015;11:1037-42

20. Okuyama Kishima M, De Oliveira CEC, Banin-Hirata BK, Losi-Guembarovski R, Brajão De Oliveira K, Amarante MK, et al. Immunohistochemical expression of CXCR4 on breast cancer and its clinical significance. Anal Cell Pathol. 2015;2015:891020.

21. Pernas S, Martin M, Kaufman PA, Gil-Martin M, Gomez Pardo P, LopezTarruella S, et al. Balixafortide plus eribulin in HER2-negative metastatic breast cancer: a phase 1, single-arm, dose-escalation trial. Lancet Oncol. 2018;19:812-24.

22. Rayson D, Lupichuk S, Potvin K, Dent S, Shenkier T, Dhesy-Thind S, et al. Canadian Cancer Trials Group IND197: a phase II study of foretinib in patients with estrogen receptor, progesterone receptor, and human epidermal growth factor receptor 2-negative recurrent or metastatic breast cancer. Breast Cancer Res Treat. 2016;157:109-16.

23. Tolaney SM, Nechushtan H, Ron IG, Schöffski P, Awada A, Yasenchak CA, et al. Cabozantinib for metastatic breast carcinoma: results of a phase II placebo-controlled randomized discontinuation study. Breast Cancer Res Treat. 2016;160:305-12.

24. Tolaney SM, Tan S, Guo H, Barry W, Van Allen E, Wagle N, et al. Phase II study of tivantinib (ARQ 197) in patients with metastatic triple-negative breast cancer. Investig New Drugs. 2015;33:1108-14.

25. Vermeulen MA, Slaets L, Cardoso F, Giordano SH, Tryfonidis K, van Diest PJ, et al. Pathological characterisation of male breast cancer: results of the EORTC 10085/TBCRC/BIG/NABCG International Male Breast Cancer Program. Eur J Cancer. 2017:82:219-27.

26. Cardoso F, Bartlett JMS, Slaets L, van Deurzen CHM, van Leeuwen-Stok E, Porter $P$, et al. Characterization of male breast cancer: results of the EORTC 10085/TBCRC/BIG/NABCG International Male Breast Cancer Program. Ann Oncol. 2018;29:405-17.

27. van der Vegt B, De Bock GH, Bart J, Zwartjes NG, Wesseling J. Validation of the $4 \mathrm{~B} 5$ rabbit monoclonal antibody in determining Her2/neu status in breast cancer. Mod Pathol. 2009;22:879-86.

28. Matte I, Lane D, Laplante C, Garde-Granger P, Rancourt C, Piché A. Ovarian cancer ascites enhance the migration of patient-derived peritoneal mesothelial cells via cMet pathway through HGF-dependent and -independent mechanisms. Int J Cancer. 2015;137:289-98.

29. Han Z, Xiao Y, Wang K, Yan J, Xiao Z, Fang F, et al. Development of a SPECT tracer to image c-Met expression in a xenograft model of non-small cell lung cancer. J Nucl Med. 2018;59:1686-91.

30. Dmitriev P, Kiseleva E, Kharchenko O, Ivashkin E, Pichugin A, Dessen P, et al. Dux4 controls migration of mesenchymal stem cells through the Cxcr4-Sdf1 axis. Oncotarget. 2016;7:65090-108.

31. Zhang Y, Yang P, Sun T, Li D, Xu X, Rui Y, et al. MiR-126 and miR-126* repress recruitment of mesenchymal stem cells and inflammatory monocytes to inhibit breast cancer metastasis. Nat Cell Biol. 2013;15:284-94.
32. Yamashita J, Ogawa M, Yamashita S, Nomura K, Kuramoto M, Saishoji T, et al. Immunoreactive hepatocyte growth factor is a strong and independent predictor of recurrence and survival in human breast cancer. Cancer Res. 1994:54:1630-3.

33. Mirisola V, Zuccarino A, Bachmeier BE, Sormani MP, Falter J, Nerlich A, et al. CXCL12/SDF1 expression by breast cancers is an independent prognostic marker of disease-free and overall survival. Eur J Cancer. 2009;45:2579-87.

34. Kobayashi T, Tsuda H, Moriya T, Yamasaki T, Kikuchi R, Ueda S, et al. Expression pattern of stromal cell-derived factor-1 chemokine in invasive breast cancer is correlated with estrogen receptor status and patient prognosis. Breast Cancer Res Treat. 2010;123:733-45.

35. Liu H, Li Z, Deng M, Liu Q, Zhang T, Guo W, et al. Prognostic and clinicopathological value of CXCL12/SDF1 expression in breast cancer: a meta-analysis. Clin Chim Acta. 2018;484:72-80

36. Moelans CB, de Ligt J, van der Groep P, Prins P, Besselink NJ, Hoogstraat M, et al. The molecular genetic make-up of male breast cancer. Endocr Relat Cancer. 2019;26:779-94.

37. Mavrogonatou E, Pratsinis $\mathrm{H}$, Kletsas D. The role of senescence in cancer development. Semin Cancer Biol. 2019;S1044-579X:30127-0.

\section{Publisher's Note}

Springer Nature remains neutral with regard to jurisdictional claims in published maps and institutional affiliations.
Ready to submit your research? Choose BMC and benefit from:

- fast, convenient online submission

- thorough peer review by experienced researchers in your field

- rapid publication on acceptance

- support for research data, including large and complex data types

- gold Open Access which fosters wider collaboration and increased citations

- maximum visibility for your research: over $100 \mathrm{M}$ website views per year

At BMC, research is always in progress.

Learn more biomedcentral.com/submissions 